\title{
Pulmonary Mechanics in Early Infancy. Sublinical Grunting in Low-Birth-Weight Infants
}

\author{
M. LINDROTH, ${ }^{(16)}$ B. JOHNSON, H. AHLSTRÖM, AND N. W. SVENNINGSEN \\ Neonatal Unit, Department of Paediatrics, and the Department of Clinical Physiology, University of Lund, Sweden
}

\begin{abstract}
Summary
Pulmonary mechanics were studied with the constant pressure body plethysmograph method in $\mathbf{7 8}$ infants during the first year of life. Registrations of breathing frequency, tidal volume, minute volume, dynamic compliance, pulmonary functional resistance, and end-expiratory resistance were made at rest and during carbon dioxide-induced hyperventilation. Data from 70 infants demonstrated strong correlations $(P<0.001)$ between all pulmonary function parameters and length. Carbon dioxide-induced hyperventilation was achieved mainly by an increased tidal volume. Pulmonary functional resistance did not change with hyperventilation, indicating wider airways during forced ventilation.

A special breathing pattern called "subclinical grunting" was found in 16 of 45 infants who were low birth weight but without clinical signs of hyaline membrane disease. The pattern was characterized by a high resistance during most of the prolonged expiration. It was identical to that previously described in cases of hyaline membrane diseases. All re-examined low-birth-weight infants with subclinical grunting developed a normal breathing pattern.
\end{abstract}

\section{Speculation}

Sublinical grunting found in preterm low-birth-weight infants might be a phenomenon of postnatal lung adaptation which can be registered by pulmonary mechanics examination.

Respiratory insufficiency is a major problem of the neonatal period, especially among low-birth-weight (LBW) infants. Increasing survival rate has been registered after neonatal intensive care, including assisted ventilation. To what extent do survivors have pulmonary sequelae after such treatment? Chest radiographs can estimate changes in lung morphology, whereas pulmonary mechanics measures important aspects of lung function. A prerequisite for clinical lung function studies is a knowledge of normal data on lung mechanics and breathing pattern.

Pulmonary mechanics studies have been reported for both newborn $(3,4,7,8,13,14)$ and older infants $(5,10,11,13,15)$. In a previous study of pulmonary mechanics, we studied 26 infants during the first year of life (2).

The aim of our present investigation was to widen our experience of lung mechanics during the first year of life including also LBW infants.

\section{PATIENTS}

The present study included $45 \mathrm{LBW}$ infants who were treated in the Neonatal Intensive Care Unit of the University Hospital in Lund. All had normal chest X-ray, and none had undergone assisted ventilation. At the time of the pulmonary mechanics examination, all were treated in incubators. Eight infants received extra oxygen because of transient tachypnea and retractions the first day of life. Another seven infants, 5 to 11 months of age, were examined to increase our data on older infants (2). Clinical data are given in Table 1. The study was approved by the local medical ethical committee, and informed consent was obtained from the parents.

\section{MATERIALS AND METHODS}

Lung mechanics was studied according to Ahlström and Jonson (1). The rate of lung volume change, $\dot{V}$, was measured by a constant pressure body plethysmograph. The intra-oesophageal pressure, $\mathrm{P}_{\mathrm{oe}}$, was measured in the lower third of oesophagus with a fluid-filled catheter. For calculations pertaining to give pulmonary mechanics, fluid-filled catheters give similar results as airfilled balloons (1). The absolute level of the intrapleural pressure can, however, be only roughly estimated. The pressure variations in the plethysmograph and oesophagus were sensed by pressure transducers (EMT 32 and EMT 34 Siemens-Elema, respectively). The frequency responses for both the volume and $\mathrm{P}_{\mathrm{oe}}$ recording systems were flat up to $20 \mathrm{~Hz}$. An electronic delay was used to limit phase shift between the signals to be less than $3 \mathrm{msec}$ up to $20 \mathrm{~Hz}$. The signals representing $\dot{V}$ and $P_{\text {oe }}$ were transmitted to a computer (PDP 8 I Digital Equipment).

For infants above $2.5 \mathrm{~kg}$, examinations were made at rest, when the patient was breathing air, and during hyperventilation. During induced hyperventilation, infants breathed a mixture of $4 \%$ carbon dioxide in $30 \%$ oxygen for $3 \mathrm{~min}$. The gas mixture was supplied through a hood kept over the infant's face. The examination was performed 20 to $30 \mathrm{~min}$ after feeding, and most infants fell asleep a few minutes after being placed in the plethysmograph box. No sedatives were given, but infants older than 2 months were not permitted to sleep for 2 to 7 hours prior to the examination.

For infants below $2.5 \mathrm{~kg}$, the method was modified to accomodate their size and to perform the examination in the neonatal ward. A small plethysmograph was constructed with an internal volume of only 14 liters. The patient was placed in the plethysmograph in the supine position with his face protruding through a latex ring of appropriate size (Face chamber mask 1-4; SiemensElema AB). This in trun was applied tightly to another similar latex ring fixed in the lid of the box (Fig. 1).

For infants below $2.5 \mathrm{~kg}$, recordings were made at rest when the patient was breathing $30 \%$ oxygen and during hyperventilation produced by $2.5 \%$ carbon dioxide in $30 \%$ oxygen. The gas mixture was supplied at a flow rate of 5 liters/min through one of the holes in the lid of the face chamber. The temperature in the plethysmograph was kept between 32 to $36^{\circ} \mathrm{C}$ by means of a radiant heater. The flow and pressure signals were transmitted to the computer mentioned above via a tape recorder (Philips Mini-log 4).

\section{CALCULATIONS}

The following pulmonary parameters were studied:

$$
\dot{\mathrm{V}}_{\mathrm{IE}}=\begin{aligned}
& \text { ventilation, } 1 \times \min ^{-1} \text {, determined from } \dot{\mathrm{V}} \text { at inspiration } \\
& \text { and expiration }
\end{aligned}
$$


Table 1. Clinical data (body length, weight, age, and oxygen supply at examination) and diagnoses

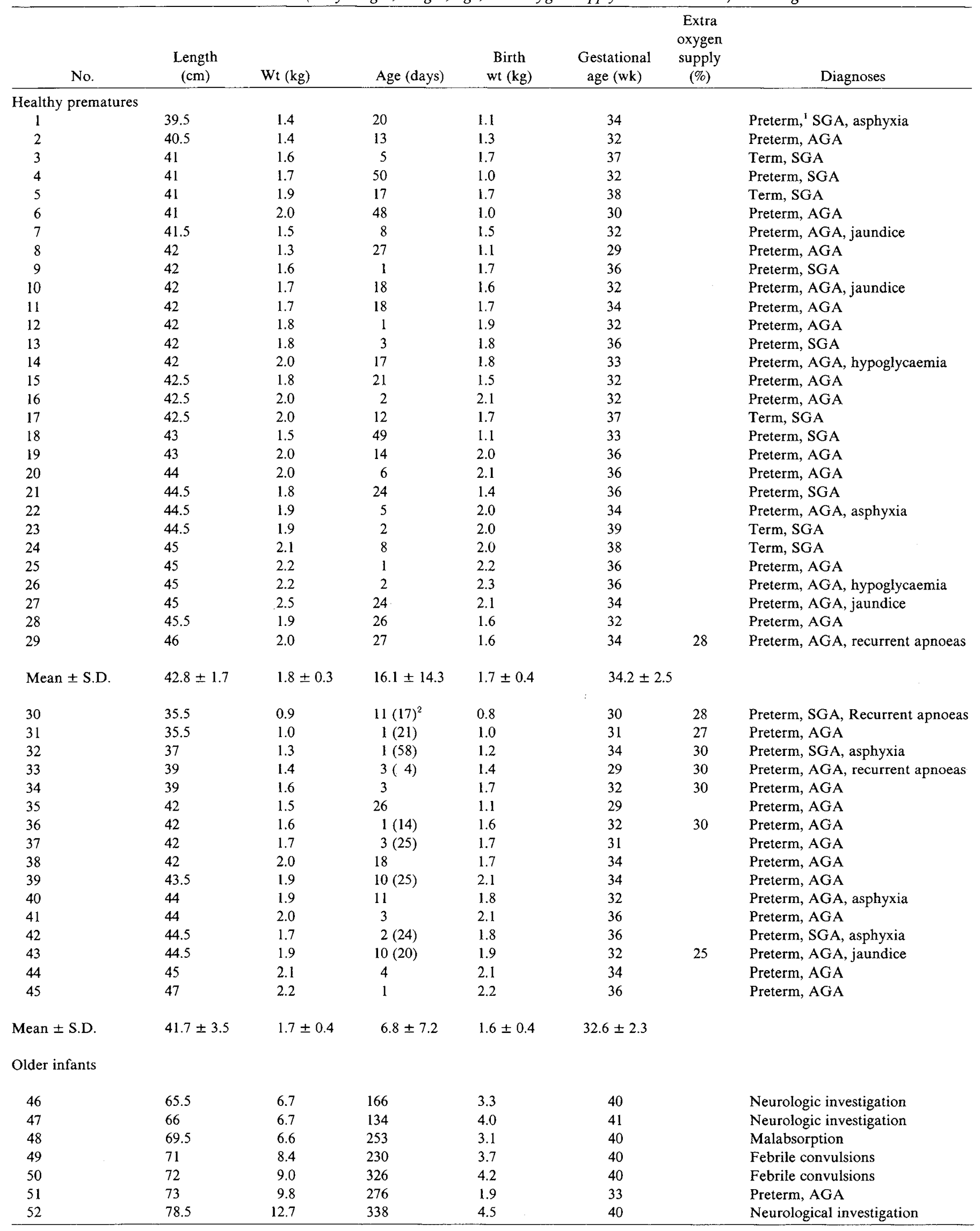

' Preterm, gestational age less than $37 \mathrm{wk}$; SGA, small for gestational age; asphyxia = Apgar score of less than 7; AGA, appropriate for gestational age.

${ }^{2}$ Numbers in parentheses, age at re-examination. 


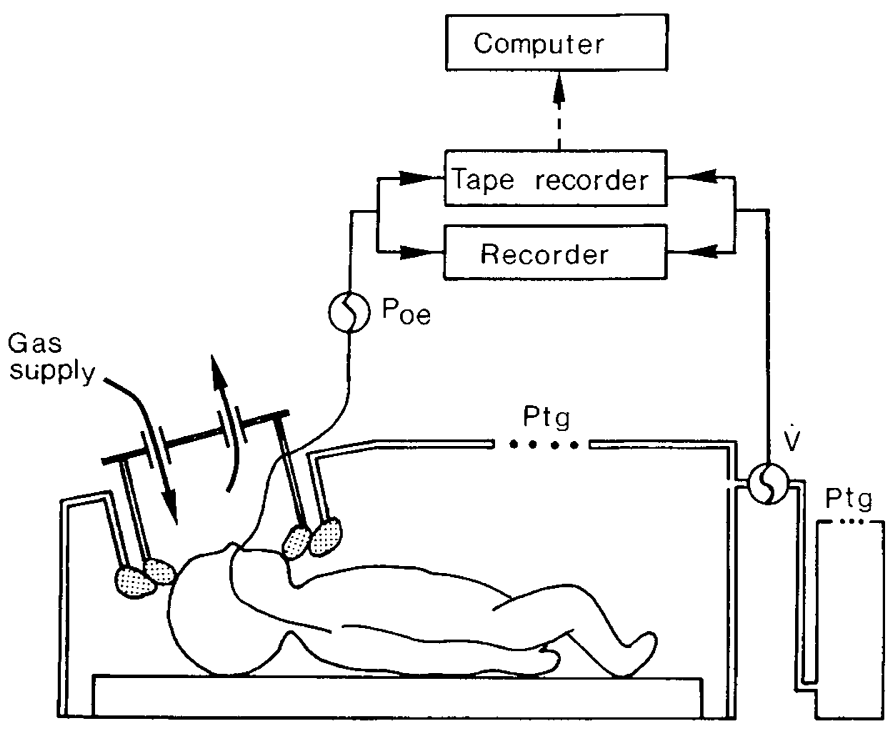

Fig. 1. Schematic drawing of the equipment. Ptg, pneumotachograph screen in the walls of the body plethysmograph and compensation chamber; $P_{o e}$ and $\dot{V}$, transducers for oesophageal pressure and air flow measurements. The signals are checked on a direct-writing recorder (Mingograph 81, Siemens-Elema AB).

$$
\begin{aligned}
\mathrm{f}= & \text { frequency, min }{ }^{-1} \\
\mathrm{~V}_{\mathrm{T}}= & \text { tidal volume }(\mathrm{ml}) \\
\mathrm{C}_{\mathrm{dyn}}= & \text { dynamic compliance, } \mathrm{ml} \times \mathrm{cm} \mathrm{H}_{2} \mathrm{O}^{-1} \text {, is the tidal vol- } \\
& \text { ume divided by the pressure difference between end- } \\
& \text { inspiration and end-expiration } \\
\dot{\mathrm{W}}_{\text {res }}= & \text { power }(\mathrm{mW}) \text { is the work rate against pulmonary viscous } \\
& \text { resistance } \\
\mathrm{R}_{\mathrm{f}}= & \text { functional pulmonary resistance, cm } \mathrm{H}_{2} \mathrm{O} \times 1^{-1} \times \mathrm{sec}, \\
& \text { is calculated as } \mathrm{R}_{\mathrm{f}}=\dot{\mathrm{W}}_{\text {res }} \times \dot{\mathrm{V}}_{\mathrm{IE}}{ }^{-2} \times 7.441 \\
\mathrm{R}_{\mathrm{eI}}= & \text { pulmonary resistance at end of inspiration, cm } \mathrm{H}_{2} \mathrm{O} \times \\
& 1^{-1} \times \text { sec, calculated from the pressure-flow loop drawn } \\
& \text { by the computer (Fig. } 2) \\
\mathrm{R}_{\mathrm{eE}}= & \text { pulmonary resistance at end of expiration, cm } \mathrm{H}_{2} \mathrm{O} \times \\
& 1^{-1} \times \text { sec, calculated as } \mathrm{R}_{\mathrm{eI}}(\text { Fig. } 2) \\
\mathrm{T}_{\mathrm{I}} \%= & \text { the relative inspiratory time, expressed as percentage of } \\
& \text { the total breath time, is calculated from a series of } \\
& \text { breaths in steady state at rest and hyperventilation: } \mathrm{T}_{\mathrm{I}} \% \\
& =\mathrm{T}_{\mathrm{I}} \times\left(\mathrm{T}_{\mathrm{I}}+\mathrm{T}_{\mathrm{E}}\right)^{-1} \times 100
\end{aligned}
$$

$\mathbf{T}_{\mathrm{E}} \%=$ the relative expiratory time (\%) calculated as $\mathrm{T}_{\mathbf{I}} \%$

For regression calculations, we have used the logarithm of respiratory functicn in relation to length. The reason for this was that for infants below and over $50 \mathrm{~cm}$ length, the variances were inhomogeneous for non-log respiratory quantities, whereas they were homogeneous for $\log$ pulmonary functions.

The normal range was defined as the $95 \%$ confidence limits for individual observations (12).

Comparisons of the residuals from the common regression line from infants below and over $50 \mathrm{~cm}$ length showed that the residuals had significantly different standard deviations for $C_{\text {dyn }}$ both at rest and during hyperventilation $(P<0.01)$. This led to inappropriately wide confidence limits for the longer infants. For this reason, we have used separate regression equations for infants below and over $50 \mathrm{~cm}$ length as far as $C_{d y n}$ is concerned.

The residuals around the regression lines were found to be normally distributed in all calculations.

\section{STATISTICS}

The computer calculated means, standard deviations, correlation coefficients, and contants in linear regressions for selected groups. It also drew xy-diagrams with the regression line and $95 \%$ confidence limits for this line and for individual observations. The
$F$ test and two-tailed Student's $t$ test were used to examine differences between groups.

\section{RESULTS}

\section{TOTAL MATERIAL}

A total number of $45 \mathrm{LBW}$ and seven older infants were investigated. One infant with apnea due to immaturity and seven with the breathing pattern of "subclinical grunting" (vide infra) were not included in the data. The remaining 44 infants were pooled together with 26 infants aged $1 / 2$ to $81 / 2$ months from our previous study (2). Our investigation thus comprised 70 infants in whom we examined certain factors relevant to pulmonary mechanics during the first year of life.

The individual values of the different respiratory parameters obtained at rest and during hyperventilation are available from the authors. Pulmonary quantities were correlated to various growth parameters such as weight, length, length ${ }^{2}$, length $^{3}, \log$ length, body surface area, age, and maturity expressed as postconceptual age (= gestational age + postnatal age). The correlation coefficients for each pulmonary quantity were essentially equal for each of the different growth parameters, except for age, in which the case the correlations were constantly lower. As in our previous study, we have chosen length as growth parameter. A summary of the regression analyses are given in Table 2 . Double regressions in which the different lung function parameters were correlated to combined growth parameters did not provide improved correlations.

$$
\dot{\mathrm{V}}_{\mathrm{IE}}, \mathrm{V}_{\mathrm{T}}, \text { AND f }
$$

There was a strong correlation of $\dot{V}_{\mathrm{IE}}$ and $\mathrm{V}_{\mathrm{T}}$ at rest to length (Table 2; figs. 3 and 4). During carbon dioxide-induced hyperventilation, the mean increase of the paired comparison of $\dot{V}_{\text {IE }}$ was 47 $\pm 28 \%$ which was highly significant $(P<0.001)$. The increased ventilation was achieved by a $38 \pm 26 \%$ increase of $\mathrm{V}_{\mathrm{T}}(P<$ $0.001)$, whereas the mean increase of $f$ was $10 \pm 21 \%(P<0.001)$. The percentage changes for $\dot{\mathrm{V}}_{\mathrm{IE}}$ and $\mathrm{V}_{\mathrm{T}}$ during hyperventilation were somewhat higher for infants above $50 \mathrm{~cm}$ length, but these differences were not statistically significant. Infants below $50 \mathrm{~cm}$ length who underwent a strictly standardized $\mathrm{CO}_{2}$ challenge

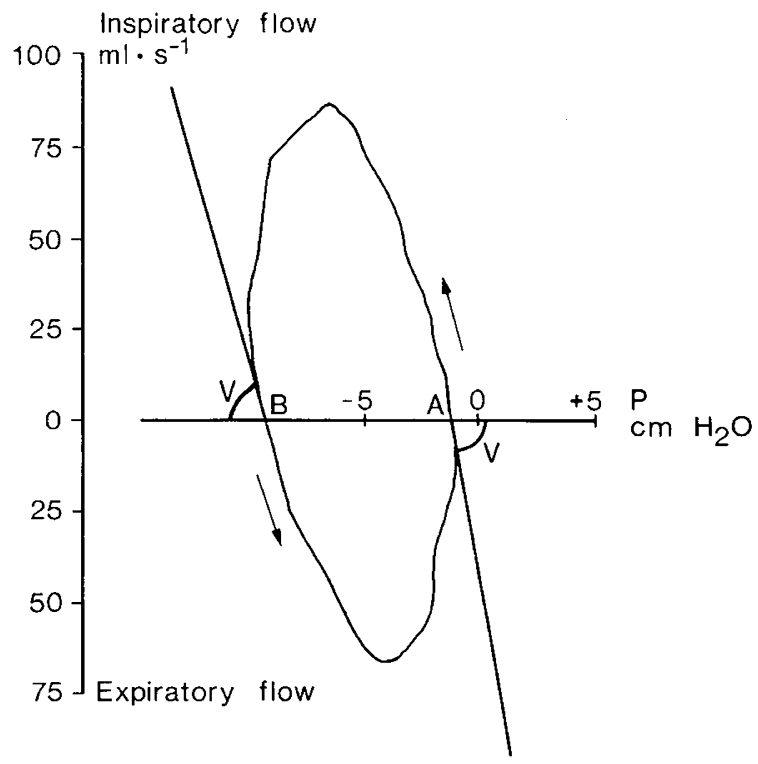

Fig. 2. Pressure-flow loop of normal type. The inspiration starts at $A$ and ends at $B$. The resistance at the end of inspiration and expiration is calculated from the angle, $v$, between the tangent of the loop when it crosses the abscissa. $C_{0} t$ of the angle $\mathrm{v}$ is proportional to $\mathrm{dP}_{\text {oe }} / \mathrm{d} \dot{\mathrm{V}}$, i.e., resistance. 
Table 2. Correlation between various respiratory quantities $(y)$ and length $(x)$ according to the formula $y=a+b x$

\begin{tabular}{|c|c|c|c|c|c|c|c|}
\hline $\begin{array}{l}\text { Pulmonary } \\
\text { parameter }\end{array}$ & $\begin{array}{c}\text { groups of } \\
\text { infants }\end{array}$ & $N$ & $\mathrm{a}$ & $b$ & $\mathrm{SD}^{1}$ & $r$ & $\begin{array}{c}\text { Significance } \\
(P)\end{array}$ \\
\hline $\mathrm{f}$ & & 70 & 84.060 & -0.7224 & 14.40 & -0.48 & $<0.001$ \\
\hline $\log \dot{\mathrm{V}}_{\mathrm{IE}}$ & & 70 & -0.8122 & 0.0155 & 0.1183 & 0.82 & $<0.001$ \\
\hline $\log \dot{\mathrm{W}}_{\text {res }}$ & & 70 & -0.3210 & 0.0209 & 0.2604 & 0.66 & $<0.001$ \\
\hline $\log C_{d y n}$ & $<50 \mathrm{~cm}$ & 46 & -1.820 & 0.0540 & 0.1840 & 0.58 & $<0.001$ \\
\hline $\log C_{d y n}$ & $->50 \mathrm{~cm}$ & 24 & -0.2202 & 0.0177 & 0.1174 & 0.76 & $<0.001$ \\
\hline $\log C_{d y n}$ & $>50 \mathrm{~cm}$ & hv 24 & -0.2375 & 0.0183 & 0.1184 & 0.77 & $<0.001$ \\
\hline $\log C_{d y n}$ & All & hv 70 & -0.3489 & 0.0202 & 0.1728 & 0.79 & $<0.001$ \\
\hline $\log R_{f}$ & & 70 & 2.1840 & -0.0103 & 0.1658 & -0.56 & $<0.001$ \\
\hline $\log R_{f}$ & & hv 70 & 2.1310 & -0.0100 & 0.1194 & -0.67 & $<0.001$ \\
\hline $\log R_{e I}$ & & hv 64 & 1.9380 & -0.0110 & 0.1860 & -0.53 & $<0.001$ \\
\hline $\log R_{\mathrm{eE}}$ & & hv 64 & 1.9280 & -0.0102 & 0.1784 & -0.52 & $<0.001$ \\
\hline
\end{tabular}

${ }^{1} \mathrm{SD}$, residual standard deviation; r, coefficient of correlation; hv, values obtained during hyperventilation.

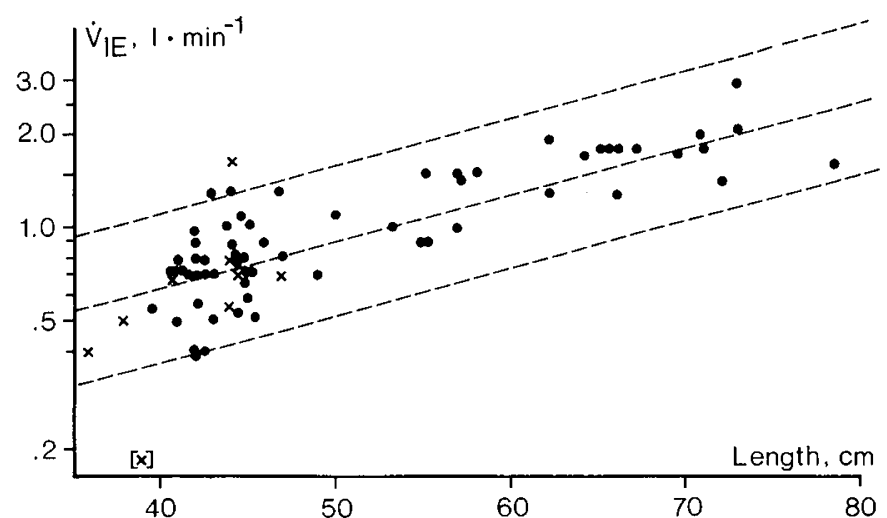

Fig. 3. $\dot{\mathrm{V}}_{\mathrm{IE}}(\log$ scale) at rest in relation to length. - - -, regression line and $95 \%$ confidence limits for individual observations ( $\log \dot{\mathrm{V}}_{\mathrm{IE}}=$ $-.8122+.0155 \times$ length). $\bullet$, normal infants; $x$, infants with previous subclinical grunting; [x], patient 33, see text.

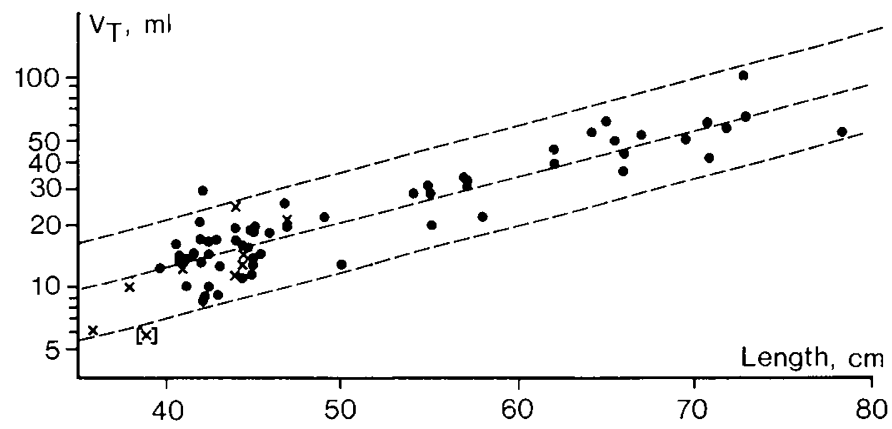

Fig. 4. $V_{T}$ (log scale) at rest in relation to length. - - - , regression line and $95 \%$ confidence limits for individual observations $\left(\log \mathrm{V}_{\mathrm{T}}=\right.$ $0.1681+0.0228 \times$ length). Symbols, see Fig. 3 .

showed no correlation between the $\mathrm{CO}_{2}$-induced changes and length, age, or maturity.

As expected, $f$ was inversely correlated to length (Table 2 ) but there was a large range, especially among the smallest infants. The relative inspiratory time, $\mathrm{T}_{\mathrm{I}} \%$, did not differ at rest or during hyperventilation ( $40 \pm 6.5$ and $42 \pm 6.0 \%$, respectively; $P>0.05$ ). $\mathrm{T}_{\mathrm{I}} \%$ was similar for small and large infants.

\section{DYNAMIC COMPLIANCE}

The relationship $C_{d y n}$ to length is shown in Figure 5. As explained under "Calculations," we have used separate regression

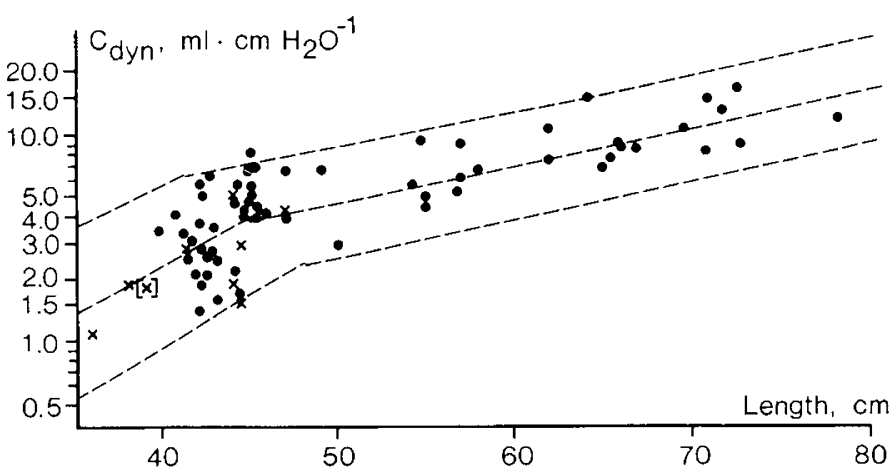

Fig. 5. Dynamic compliance (log scale) during hyperventilation in relation to length. - - - , regression lines and 95\% confidence limits for individual observations. As explained under "Calculations," separate regressions have been calculated for infants below and over $50 \mathrm{~cm}$ length. Regression equations are given in Table 2. Symbols, see Fig. 3.

calculations for infants below and over $50 \mathrm{~cm}$ length. Strictly applied, these calculations would have resulted in a sudden fall of expected values and $95 \%$ confidence limits when an infant became $50 \mathrm{~cm}$ long. This obviously does not represent a biologic reality but a shortcoming of the model used in the statistical analysis. Rather than adapting the statistical model in some complicated way to our findings, we have preferred to discuss the expected values and normal limits from a biologic and clinical viewpoint.

The lower 95\% confidence limit is, in general, the important borderline for $\mathrm{C}_{\text {dyn }}$ in order to differentiate between health and disease in single infants. The two lower $95 \%$ confidence limit lines cross each other close to $50 \mathrm{~cm}$, indicating that this limit is adequately described on a statistical basis.

To obtain smooth junction for predicted values and $95 \%$ confidence limits, we have choosen to extrapolate the lines for the longer infants until they cross the lines for shorter ones. The regression for data above $50 \mathrm{~cm}$ probably describes the growth for mature infants. Shorter infants who are, to a varying extent more immature, should show larger deviations towards lower values of $\mathrm{C}_{\mathrm{dyn}}$, as described by the regression. It appears unlikely that shorter infants would have compliance above those expected for longer, more mature ones. The way we have chosen to describe our predicted values reflects this view and describes our data adequately, although we realize that it is somewhat arbitrary. Even if the method is questioned, this description of normal range seems practically adequate for infants around $50 \mathrm{~cm}$ length but is uncertain for infants $40 \mathrm{~cm}$ or shorter because of few observations. 


\section{RESISTIVE PROPERTIES}

The relation of $R_{f}$ and its reciprocal, conductance $\left(G_{f}\right)$, to length during hyperventilation is shown in Fig. 6. Paired comparisons of $\mathrm{R}_{\mathrm{f}}$ during hyperventilation and rest showed a nonsignificant decrease during hyperventilation. The residual standard deviation around the regression line during hyperventilation was, however, significantly lower $(P<0.01)$. Because this implies a narrower normal range, we have used measurements during hyperventilation in clinical practice.

The values for resistance at end-inspiration, $R_{e I}$, and end-expiration, $R_{\mathrm{eE}}$, were significantly lower than those for $\mathrm{R}_{\mathrm{f}}(P<0.001)$. At paired comparison, $\mathrm{R}_{\mathrm{el}}$ was somewhat but not significantly lower than $R_{\mathrm{eE}}$.

For clinical use, we have compiled tables for expected values and $95 \%$ confidence limits for $f, V_{I E}$, and $V_{T}$ at rest and $C_{d y n}, R_{f}$, and $R_{\mathrm{eE}}$ during hyperventilation for different lengths. The tables are available from the authors.

\section{SUBCLINICAL GRUNTING}

Among 45 examined LBW infants, 16 (infants 30 to 45 ) had a special breathing pattern, illustrated in Figure 7, which we name subclinical grunting. The expiratory flow started normally but was soon retarded during a prolonged expiratory phase in spite of an increasing oesophageal pressure. This implies a pronounced increase of expiratory resistance. Towards the very end of expiration, flow was suddenly accelerated, in most cases in spite of a fall in oesophageal pressure, which indicates a sudden decrease of resistance. At the end of expiration, resistance was still somewhat higher than normal.

Upon examination of parameters involved in lung mechanics, subclinical grunting was usually found both at rest and during hyperventilation but could fluctuate during the same examination period.

Comparisons were done between the individual values obtained at subclinical grunting and the expected ones according to the regression equations in Table 2 . Patients with subclinical grunting had an average $\mathrm{R}_{\mathrm{f}}$ value at rest that was 2.2 times higher $(P<$ $0.001)$ and during hyperventilation 2.6 times higher $(P<0.001)$ than the expected values. The mean $R_{\mathrm{eE}}$ value was 1.3 times higher $(P<0.001)$, whereas there was no difference in $\mathrm{R}_{\mathrm{el}}$. Other differences include a $30 \%$ decrease of $\mathrm{f}(P<0.001)$ and a $30 \%$ decrease of $\dot{\mathrm{V}}_{\mathrm{IE}}(P<0.001)$ at subclinical grunting. The $3 \%$ decrease of $V_{T}$ and $1 \%$ decrease of $C_{d y n}$ were not significant. The relative expiratory time at subclinical grunting was $70 \%$ compared to $60 \%$ for nongrunters $(P<0.001)$.

Seven of the 16 patients with this breathing pattern received extra oxygen supply (Table 1). This was started because of transient retractions or tachypnea during the first day of life. Apart from this, there were no clinical characteristics among these 16

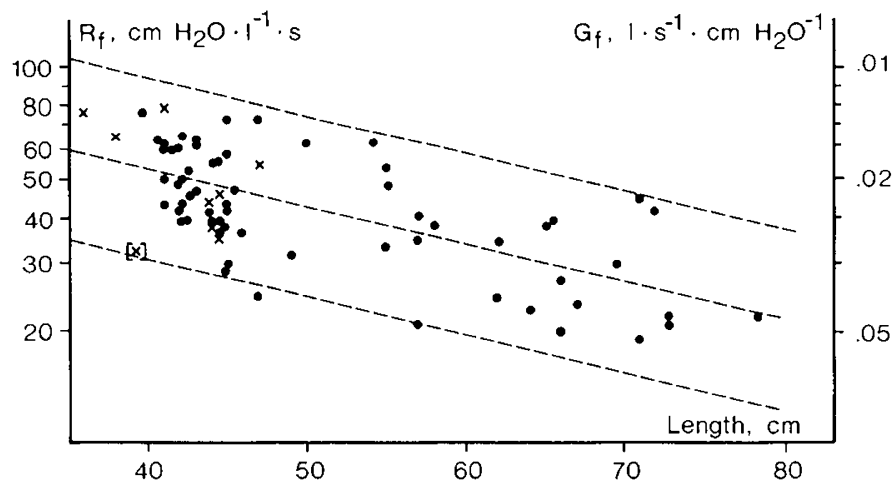

Fig. 6. Pulmonary resistance (left) and conductance (right) (log scale) during hyperventilation in relation to length. - - - , regression line and $95 \%$ confidence limits for individual observations $\left(\log R_{f}=2.131-0.01\right.$ $\times$ length). Symbols, see Fig. 3.
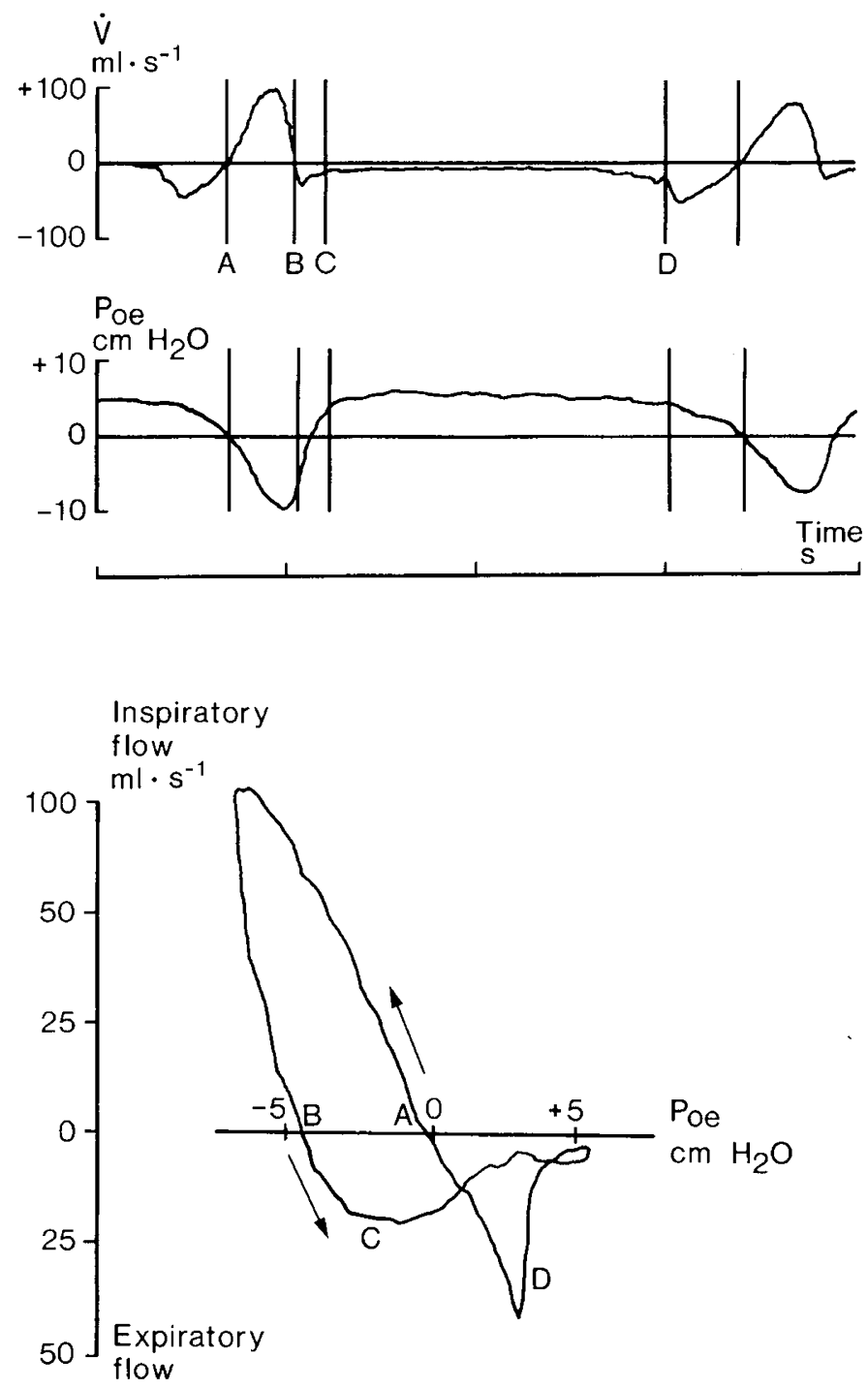

Fig. 7. Flow, $\dot{\mathrm{V}}$, and oesophageal pressure, $\mathrm{P}_{\mathrm{oe}}$, tracing (above) and pressure-flow loop (below) from an infant with subclinical grunting. A rapid inspiration starts at $A$ and ends at $B$. The expiratory flow is retarded at $C$. At the end of expiration, flow is accelerated, $D$, in spite of a decreasing $\mathbf{P}_{o e}$. $P_{o e}$ is positive during most of expiration.

patients. Not even listening over the neck with a stethoscope revealed any grunting sound. However, patients with subclinical grunting had a lower mean postnatal age, and all were preterm. Among 18 preterm infants examined during the first wk of life, subclinical grunting was present in 10 . As regards weight, all but one infant that weighed less than $1.8 \mathrm{~kg}$ and was less than 4 days old showed this breathing pattern. All had normal body temperature during incubator treatment, and there were no feeding problems. Because of the absence of clinical correlates, we name this breathing pattern subclinical grunting.

Nine of the patients with subclinical grunting were re-examined 1 to 7 wk later, and all had developed a normal breathing pattern. At the re-examination, none required extra oxygen supply. The data pertaining to parameters of pulmonary mechanics also became normal (Figs. 3 to 6). On the day of re-examination, one infant (infant 33) developed apnoeic spells later that day and had to be treated in a ventilator for 6 days. Pulmonary mechanics a few hr before the apneas showed no subclinical grunting. The values of $\dot{V}_{\mathrm{IE}}$ and $\mathrm{V}_{\mathrm{T}}$ were, however, very low (Figs. 3 and 4). This may have been caused by a decrease in the respiratory drive necessitating assisted ventilation later on the same day. After the assisted ventiltion treatment, the patient had normal pulmonary 
mechanics and has since then been well. Another patient with subclinical grunting (infant 30 ) developed recurrent apneas but did not need assisted ventilation. These two patients were the only ones with subclinical grunting that developed respiratory disease. The data at re-examination, obtained in infants who had previously showed subclinical grunting, were included in the studies with the exception of those of patient 33 .

\section{DISCUSSION}

Our previous study of pulmonary mechanics during the first year of life was limited to infants weighing more than $2 \mathrm{~kg}$ and older than $2 \mathrm{wk}$. The construction of a small mobile body plethysmograph for the present study made it possible to investigate neonates even below $1.0 \mathrm{~kg}$.

Data from our previous and current studies (2) represent investigations into the pulmonary mechanics of 70 infants during the first year of life. To predict respiratory quantities, we have chosen length as a body size indicator instead of weight or body surface area because these factors may be more variable due to the low amounts of subcutaneous fat in infants with chronic diseases.

In clinical work, an infant is sometimes examined repeatedly. It is then important that the normal limits follow a continuous function with relation to body size. When the present material of infants less than $50 \mathrm{~cm}$ length was analyzed, the regression equations were similar to those for longer infants with respect to ventilation and resistance. Therefore, the data were pooled. For compliance, separate regressions were needed for infants below and over $50 \mathrm{~cm}$. The need for normal limits without irregular changes could, however, be fulfilled as explained under "Results."

- As in our previous study, the values of pulmonary functions reported in this work showed good agreement with data in other studies $(3,5,7,10,11,15)$. The increased ventilation during carbon dioxide-induced hyperventilation was due mainly to an increased tidal volume. This was valid even for the most immature infants.

Pulmonary functional resistance was calculated from the measured work rate against pulmonary resistance and ventilation. The resistance during hyperventilation did not differ from the values obtained at rest. With unchanged airways, the resistance would be expected to increase with increased flow rate. The constant $\mathbf{R}_{\mathbf{f}}$ values thus indicate that the airways widen as the flow rate increases. The stable $R_{f}$ has the practical implication that individual $R_{f}$ values can be compared independently of ventilation.

Strong linear relationships have been shown between resistance or conductance and lung volumes in other studies $(5,13)$. We have tried to measure lung volumes with the body plethysmograph and gas dilution techniques but did not succeed because the unsedated infants were awakened by the experimental manipulations. Stocks and Godfrey (13) have studied specific airway conductance, $\mathrm{SG}_{\mathrm{aw}}$ (= airway conductance divided with the total gas volume, TGV) during infancy. In preterm infants, $\mathbf{S G}_{\mathrm{aw}}$ decreased rapidly with increasing maturity up to $40 \mathrm{wk}$. Later on, $\mathbf{S G}_{\mathrm{aw}}$ was fairly stable during the first year. In our material, the regression lines for $G_{f}$ over maturity had the same slope for infants below and over 40 wk. This supports the opinion of Stocks and Godfrey that the decrease of $\mathrm{SG}_{\mathrm{aw}}$ with maturity is due more to an increase in $\mathrm{TGV}$ (alveolization) than to increase conductance (airway increment). Thus $\mathrm{SG}_{\mathrm{aw}}$ may be rather misleading if it is used as a measure of airway properties in small infants. By using $R_{f}$, this problem is avoided. Thus, it is not necessary to take maturity but only length into consideration for prediction of normal values.

Values of $R_{e I}$ and $R_{e e}$ were obtained from the pressure-flow loops. As expected, the resistance at zero-flow was significantly lower than $R_{f}$. We have found that $R_{e E}$ and the pressure-flow loop configuration are useful to distinguish different causes of increased resistance, e.g., retained mid-inspiratory flow at upper airways obstruction, reduced expiratory flow, and high $\mathrm{R}_{\mathrm{eE}}$ at obstructive lung disease and the special pattern of subclinical grunting.
One-third of the examined LBW infants had a special breathing pattern at their first examination, characterized by a prolonged expiration and a high resistance during most of the expiration. The pressure and flow tracings were of the same nature as in Harrison et al's (6) study of grunting in hyaline membrane disease. According to Harrison et al., grunting is caused when air is forced by an increased intrathoracic pressure through a partially closed glottis during most of expiration. The effect should be to prevent hypoxia by increasing TGV and thus keep alveoli in the lungs open.

None of our patients with subclinical grunting had audible grunting, but some had transient tachypnea and retractions with seven of 16 receiving extra oxygen supply. It is possible that patients with subclinical grunting have a low FRC (functional residual capacity) and a tendency towards hypoxia for which they, more or less successfully, compensate by this breathing pattern. Krauss and Auld (9) in a study of 26 prematures found that all had trapped gas for various times and that gas trapping persisted longer in the smallest infants. One reason for this could be that the airways in immature infants have a tendency to collapse during expiration, as shown by Burnard et al. (3). Grunting of various degrees should oppose the collapse of airways and improve oxygenation by increasing FRC. If hypoxia per se was the factor that triggered subclinical grunting, it is difficult to explain why nine infants without clinical signs of hypoxia in $21 \%$ oxygen in the incubator had subclinical grunting while breathing $30 \%$ oxygen during the pulmonary mechanics examination. It might be pulmonary or thoracic stretch receptors at low FRC that give rise to subclinical grunting.

Subclinical grunting was only found in preterm LBW infants, especially during the first 2 wk of life.

According to the present results, this is a common breathing pattern of LBW infants in the neonatal period.

\section{REFERENCES AND NOTES}

1. Ahlström, H., and Jonson, B.: Pulmonary mechanics in infants. Methodological aspects. Scand. J. Respir Dis., 55: 129 (1974).

2. Ahlström, H., and Jonson, B.: Pulmonary mechanics during the first year of life. Scand. J. Respir Dis., 55: 141 (1974).

3. Burnard, E. D., Grattan-Smith, P., Picton-Warlow, C. G., and Grauaug, A.: Pulmonary insufficiency in prematurity. Aust. Paediatr. J., 1: 12 (1965).

4. Cook, C. D., Sutherland, J. M., Segal, S., Cherry, R. B., Mead, J., Mcllroy, M. B., and Smith, C. A.: Studies of respiratory physiology in the newborn infant. III. Measurements of mechanics of respiration. J. Clin. Invest., 36: 440 (1957).

5. Doershuk, C. F., Downs, T. D., Matthews, L. W., and Lough, M. D.: A method for ventilatory measurements in subjects 1 month -5 years of age. Normal results and observations in disease. Pediatr. Res., 4: 165 (1970).

6. Harrison, V. C., Heese, H. B., and Klein, M.: The significance of grunting in hyaline membrane disease. Pediatrics, 41: 549 (1968).

7. Hjalmarsson, $\mathrm{O}$.: Mechanics of breathing in newborn infants with pulmonary disease. Acta Paediatr. Scand. Suppl., 247: (1974).

8. Karlberg, P., and Koch, G.: Respiratory studies in newborn infants. III. Development of mechanics of breathing during the first week of life. A longitudinal study. Acta Paediatr. Scand. Suppl., 135: 124 (1962).

9. Krauss, A. N., and Auld, P. A.: Pulmonary gas trapping in premature infants. Pediatr. Res., 5: 10 (1971).

10. Krieger, U.: Studies on mechanics of respiration in infancy. Am. J. Dis. Child., 105: 439 (1963).

11. Phelan, P. D., and Williams, H. E.: Ventilatory studies in healthy infants. Pediatr. Res., 3: 425 (1969).

12. Snedecor, G. W.: Statistical Methods. (Iowa State University Press, Iowa, 1956).

13. Stocks, J., and Godfrey, S.: Specific airway conductance in relation to postconceptional age during infancy. J. Appl. Physiol., 43 : 144 (1977).

14. Swyer, P. R., Reiman, R. C., and Wright, J. J.: Ventilation and ventilatory mechanics in the newborn. J. Pediatr., 56: 612 (1960).

15. Wohl, M. E., Stigol, L. C., and Mead, J.: Resistance of the total respiratory system in healthy infants and infants with bronchiolitis. Pediatrics, 43: 495 (1969).

16. Requests for reprints should be addressed to: Dr. Magnus Lindroth, Department of Paediatrics, University Hospital, S-221 85 Lund, Sweden.

17. This research was supported by grants from the Swedish Medical Research Council (Nos. 29X-4732 and 14X-02872) and the Swedish National Association against Chest and Heart Diseases.

18. Received for publication November $6,1979$.

19. Accepted for publication October $22,1980$. 